\title{
RMIT University and the University of Newcastle
}

\author{
Craig Batty and Allyson Holbrook
}

\section{Contributing to knowledge in creative writing research: what, where, how?}

\begin{abstract}
:
There is general agreement that doctoral research should show 'originality', but there is less agreement about what that means or how it is distinguished from 'contribution'. There is also a strand in the literature that attests that different disciplines, especially relative newcomers to the doctorate such as the creative arts, privilege different qualities of originality and forms of contribution. This prompts the question: what constitutes an original contribution in the field of creative writing? Drawing on the growing literature on creative doctorates, reference to a number of examiner reports collected for a larger project, and reflections on supervising and examining creative writing PhDs, this paper explores the various forms of contribution that characterise the discourse on knowledge creation and dissemination in creative writing research.
\end{abstract}

Biographical notes:

Dr Craig Batty is Associate Professor of Screenwriting and Creative Practice at RMIT University, Australia. He is author and editor of over 60 books, book chapters, journal articles and refereed conference proceedings. His current research on doctoral education in creative disciplines is being undertaken with the Centre for the Study of Research Training and Impact (SORTI) at the University of Newcastle, Australia. Craig is also Adjunct Professor at Central Queensland University (Australia), and Visiting Research Fellow at Bournemouth University (UK).

Professor Allyson Holbrook, University of Newcastle, is currently a member of the Australian Research Council (ARC) College of Experts, the founding Director of the Centre for the Study of Research Training and Impact (SORTI), and recipient of a number of ARC Discovery Projects on PhD Examination and the Doctoral Learner. For five years she chaired the University of Newcastle's Human Research Ethics Committee, and her most recent ARC project with the SORTI team is focussed on the metacognitive development of doctoral learners.

Keywords:

Creative writing research - Doctoral research - Contribution to knowledge - Originality - Doctoral supervision - Thesis examination 


\section{Introduction}

In a paper that explored how examiners, supervisors and others interpret the concept of 'originality' in connection with examining PhD theses, Clarke and Lunt (2016) concluded that even though the concepts of originality and contribution to knowledge are 'closely related', they should be defined separately because the latter may not signify 'truly ground-breaking, original, or new work'. They found that academics combine, use and nuance the words, 'significant', 'original' and 'contribution' to distinguish the quality of the research, noting that 'significant contribution' could be regarded among the highest of accolades (Clarke and Lunt 2016: 118). For new fields of doctoral research such as the creative arts, it is salient to note that while there is a clearly understood expectation that $\mathrm{PhD}$ research will be original, understandings of what this looks like can vary across disciplines and subject areas (Clarke and Lunt 2016). Even in extant studies of creative arts doctorates (e.g. Phillips et al. 2008, Webb et al. 2010), while questions are posed about originality and contribution, there is little focus on what these terms actually mean and how they might be defined and measured. Moreover, these studies still grapple with purpose of the creative work and its relationship with the written work, rather than how the thesis as a whole contributes to knowledge. This prompts us to ask, what forms do understandings of originality and contribution take in creative fields; and more specifically, what does a 'significant' contribution to knowledge look like in the creative writing $\mathrm{PhD}$ ?

There is a general acceptance in the academy that in order to guide candidates, supervisors themselves need to have a strong grasp of 'what constitutes an acceptable contribution' at the level of discipline, sub-discipline and 'within the specialism' (Parry 2007: 10). However, in newer doctoral disciplines it stands to reason that such understandings will take time to develop, and require both a concerted effort and a critical mass of research activity to build and test them (see Dally et al. 2004). This speaks to the creative arts broadly, wherein practitioner-teachers from art, design and film schools were drawn into the academy relatively recently and required to 'up skill' with a doctoral qualification. More often than not this involved 'retrofitting' professional practice as research (see Baker 2014, Wilson 2014). As creative arts disciplines mature, it remains to be determined if there is a growing or emerging consensus about research contribution at doctoral level; and at the very least there is a need to explore the state of play in order to open up the area for further debate.

In this paper we draw on our experiences as supervisors and doctoral education researchers to tease apart the question of contribution in creative writing research, and suggest ways to ensure that the $\mathrm{PhD}$ achieves what it needs to achieve, as a qualification and not least, in relation to the future of the discipline. In particular, discussing various methodologies and how these produce particular types of thesis, we focus on where contribution resides: in the creative work only; in the dissertation/exegesis only; or in the thesis as a whole? While these questions might for some yield obvious answers, from the detail we present below there is a surprising breadth of difference in how contribution is conceived of and articulated. 


\section{The role of the creative writing $\mathrm{PhD}$}

The expectation of the creative writing $\mathrm{PhD}$ early on was the production of a major creative work, such as a novel or book of poetry, plus 'a sort of critical journal, a reflective account of processes undertaken while creating the accompanying work, having a close umbilical relationship to it' (Krauth 2011). Over time, however, and in response to questions of rigour, originality and the construction of an integrated thesis (i.e. argument), we can see that the accompanying written work has shifted 'from reflective text, to parallel text, to plaited text' (Krauth 2011). This suggests a more holistic approach to the $\mathrm{PhD}$, wherein - ideally, perhaps - the contribution to knowledge is not in the creative work or the exegesis/dissertation, but rather across both; found within the relationship of the two (or more) parts. This is evident in what Krauth states at the end of his article: 'The creative writing exegesis has picked up momentum on its liberating trajectory. A similar trajectory is now predicted for the creative component' (Krauth 2011).

Picking up on this idea of an integrated approach to contribution, Watkins and Krauth (2016) ask: 'Is creative writing the discipline in the box seat for exploring and exploiting new, flexible and dynamic knowledge forms?'. Capturing the confusion and concern of some creative writing researchers about writing academic papers and framing their research with a scientific model, they argue for new ways of 'doing' and 'writing up' research that are relevant to both the discipline and the form/genre. They touch on two areas they see as offering possibilities in creative writing: fictocriticism and multimodality. Writing that fictocriticism 'offers a means to employ and play with the skill set of the writer, and that employment and play is ironically directed at understanding the act of creativity itself'; and that multimodality affords strong opportunities to collaborate and present work digitally and internationally (Watkins and Krauth 2016); we can infer that as well as being concerned with how creative writing research can be undertaken and presented, Watkins and Krauth are also advocating for new forms of knowledge contribution in the discipline.

Here we might turn to some of the literature on creative writing (or creative arts) research, which can sometimes espouse an arguably simplistic notion of what the $\mathrm{PhD}$ is. Notably, that the PhD is a creative artefact plus an exegesis (Arnold 2005); and is a research project instigated by practice (Candy 2006). Conversely, the PhD is not simply an artefact plus an exegesis: it is a singular research question (or proposition) that is undertaken via the modality of practice and some aspects of 'traditional' research, resulting in one work (a thesis) that presents itself in various ways. There are also methodological nuances to how a creative writing $\mathrm{PhD}$ is carried out and presented, wherein the contribution can be about process (e.g. practice-led research) or about a theory or idea that is explored and executed partly through practice, but is clearly evidenced via a product (e.g. research-led practice ${ }^{1}$ ).

Contribution here can be viewed quite differently, namely: is it new knowledge about one's personal understanding of their individual practice; or a new understanding of how the practice (of creative writing) relates to one or more fields of enquiry (see, for example, Batty and Kerrigan 2017, Sempert et al. 2017)? Drilling down into the concept of contribution - original, significant or otherwise - necessarily asks questions not only 
about what a candidate's work might achieve, but also where it might be evident and articulable.

Increasingly, in many of the contemporary creative writing PhDs that we are aware of, the written (or performed) word is not an adjunct to the argument being created, but rather does that work through its content and form, with the creative and critical texts/artefacts contributing as one. If, as Sempert et al. have argued, 'when fully embraced as both a frame and a form, methodology can innovate the very fabric of a work through its stitching together of methods, practice, reflections, and creative and critical outcomes' (Sempert et al. 2017: 219), then contribution can be integral and potentially evident at every level. In order to grow and strengthen the discipline, then and as has been highlighted in other creative fields - there ultimately emerges a need to focus on 'academic attributes', what 'constitutes new knowledge' and consensus on standards of the examinable components of the $\mathrm{PhD}$, 'above consensus on functional aspects and terminology’ (Dally et al. 2004, cited by Hamilton and Carson 2013: 5).

\section{Understanding contribution}

Writing about the expectation for contribution in the creative arts doctorate, through the lens of examination, Webb et al. ask: 'But do we expect this of the work as a whole, the creative artifact only, or the critical essay primarily? Most participants [in their study] considered that both elements are expected to meet these standards, but also suggested that this was setting the bar very high' (2010: 40). So, in effect, there is an emphasis on both parts ideally doing the work of the thesis, but with some indication that achievement of successful holistic contribution is indicative of outstanding work. This prompts the question about the need for clearer articulation of where the bar is set and why; and should this bar move up and down depending on the project and the candidate?

Webb et al. do follow with, 'we consider that the standard for creative doctorates should be less about production values and position in the professional marketplace, and more about the concept at the heart of the work' (Webb et al. 2010: 41). This alludes to the idea that the creative work should be assessed alongside the critical essay, using the same research-based criteria. Similar to Pakes's observation that contribution in the creative arts doctorate should be found in 'the newness of the [creative] object's cognitive content rather than its artistic originality' (Pakes, cited by Phillips et al. 2008), there is a clear sense that it is the research orientation of the creative work that should be examined, not its aesthetic qualities per se. Thus, while comprised of parts and artefacts that might stand up to industry or artistic criteria, the doctorate demands that contribution be assessed according to research intentions, processes and outcomes that collectively form a single argument - a thesis.

Also writing about the creative arts doctorate, Hamilton and Carson (2013) refer to Darren Newbury's Council of Graduate Education (UK) positioning report (1997), which outlined what he saw as the various types of new knowledge contribution made possible by creative practice research in art and design. This included 'innovations in design, aesthetic development, methods and methodologies for art and design, new understandings, models and theories of art/design, as well as empirical novelty' (cited 
by Hamilton and Carson 2013: 3). For Hamilton and Carson, agility in supervision expertise thus continues to be important in the creative arts, 'because of the many forms of $\mathrm{PhD}$ outcomes that constitute viable and valuable contributions to the field, because interdisciplinary projects are commonplace, and because supervisors continue to face shifts in the field in terms of form and practices' (2013: 4). Faced with these issues, and in reference to the qualifications standards outlined above, is it not the case that understanding and 'doing' contribution should remain constant?

There are academics who hold to the position that 'artistic research work should be evaluated on its own terms, as art, as an evidential form of innovation in its own right, without the exegetical functions of a written report, or dissertation' (Baker 2014: 46). However, if the researcher does not articulate the research who else can with any hope of doing so completely and consistently? Context is also relevant in doctoral contribution. The candidate does not enter a doctoral degree at doctoral level; they become 'doctoral' through doing research. There has to be assessable evidence of both learning and level. Contribution is one assessable element in doctoral work, and is established as indicative of level. It follows that contribution has to be consciously established, communicated by and attributable to the candidate in order to be assessed effectively. So, while there are wider debates about what might constitute research in creative fields, in relation to a doctoral degree this argument occurs in a specific examinable context. The remainder of the paper is specific to this context.

Considering what an examination might look like in a creative writing $\mathrm{PhD}$, could a leading novelist be able to identify where the contribution lies in a doctoral novel, without any prompting of what this contribution looks like and where it might be found (on the page)? Indeed, would it be the novel as a whole that contributes to knowledge; or just one aspect, such as the use of a particular perspective that shapes the way the novel is plotted, or the use of particular speech patterns in the dialogue of one of the characters? Clearly this comes back to the very question of contribution arising from the research: what is the work doing that is new, and how is it doing it? To return to the leading novelist, would this be obvious to them - given their likely expert knowledge in the field and genre - or would they need a research question at the very least, if not an articulation of the novel's research background?

On a very pragmatic level, Baker reminds us that if 'doctoral candidates understand their field adequately - that is, if they know the literature, the context, relevant critical and historical material - and understand where their project is located in relation to that, they are in a good position to find the gap in that field, just as any research project would' (Baker 2014: 34). Doctoral researchers (as learners) need to become experts in their field (to reach a level), demonstrating a command of the extant literature and practice in their specific area (see also, Gibson 2017). If they are able to contribute and, importantly, recognise their contribution to the field on the basis of this (i.e., benchmark their work against that of others to argue for originality), is it possible that examiners can judge the work as an original contribution to knowledge without being given this background? For those $\mathrm{PhD}$ projects that use practice to contribute to a theoretical domain - for example, researching gender and through the use of an original creative output, 'doing representation differently' (Berbary 2011: 186, see also Hope 2016) - 
can we really know that writer-researcher is doing that work differently, or do we need to see the evidence trail?

A danger of sidelining the importance of articulating contribution by letting the creative work 'speak for itself', is that without rigorous scaffolding it can be hard to convince readers that the work does in fact contain new knowledge. Without such scaffolding, examiners could very easily revert to what they know and/or what they feel about the work, which might not be on research terms but rather against industry or other professional standards (see below). For Forbes, writing on the music PhD:

The originality of the performance folio may be inherent where the concerts consist of premieres or where the performance mode is highly reliant on improvisation, but when more standard repertoire has been performed, then the nature and quality of the candidate's original contribution to the field needs to be clarified in the exegesis. (Forbes 2014: 276)

Here we can turn to the example of an arts-based practitioner interviewed by Jenny Wilson, for her $\mathrm{PhD}$ about those who were brought into the academy from art, design and film schools and made to undertake PhDs:

there is not really a lot of difference in what I did as a practitioner and now what I am doing as a researcher, just the awareness that it is research means that the data gathering is more disciplined and recorded, and it results in publications whereas as a practitioner, the performance is all. (Wilson 2014: 213)

The question to ask of this candidate would be: what exactly is the research output, and where is the contribution to knowledge? We can only surmise from what she says that the creative work is a site for fieldwork/data collection, with the research findings being her reflections on doing that work. In short, while those reflections contribute to knowledge about the practitioner's own process, the creative work itself does not. In this type of scenario, contribution to knowledge is only assessable through the written work because the creative work (by admission) does not do anything different to what it did outside of a research context.

To ensure that a creative work does provide a contribution in a scenario like this, it would have to be re-fashioned on the basis of that reflection, in an iterative cycle of research. The question to be asked of this approach, however, would be: on what basis does the reflection take place? Against which theories or paradigms do these reflections emerge, ensuring that the next iteration of the work is responding to research, not just responding to one's gut instinct? As Forbes has put it: 'While the primary audience for an exegesis is necessarily the examiners [...] there must be recognition that the exegesis should contain original research outcomes and reflections that would be of value to other practitioners in the field and that have been or will be submitted for refereed publication' (Forbes 2014: 275-6). For reflection to contribute to knowledge, it should occur on the basis of extant ideas, paradigms and practices, not individual, isolated thoughts and feelings.

Jerry Wellington provides an overview of some of the common phrases and expressions found in university regulations regarding 'original contribution' and the level of 'doctorateness'. These include: original work which forms an addition to knowledge; 
makes a distinct contribution to the knowledge of the subject; represents a significant contribution to learning, for example, through the discovery of new knowledge; and provides originality and independent critical ability (Wellington 2013: 1495). Arguing that " "originality", like many words in the regulations sampled [...] is one which is widely used in this context but (again like many) has a range of meanings, few of which are shared' (Wellington 2013: 1497), like us (and Newbury, above) Wellington is interested in the different forms that an 'original contribution' to knowledge can take. In creative fields broadly and creative writing specifically, what does it look like? How do we know when we see it? Importantly, how is it assessed?

\section{How do examiners discuss contribution?}

The current Australian Qualifications Framework specifies that at doctoral degree level there is need for: communication skills to present cogently a complex investigation of originality or original research for external examination against international standards and to communicate results to peers and the community; [and] expert skills to design, implement, analyse, theorise and communicate research that makes a significant and original contribution to knowledge and/or professional practice (2013: 64). This is closely mirrored in Britain and New Zealand, with their respective Higher Education qualification standards bodies, The Quality Assurance Agency for Higher Education and The New Zealand Qualifications Framework. For many examiners, for a thesis to be judged as operating at doctoral level, 'It has to offer something and it has to be able to say why the project is significant, why it's different, what it's contributing'. It would be reasonable to assume that doctoral examiners are all of the same mind on this, given the criteria outlined above, however an intriguing finding from a large study of examiner reports (Lovat et al. 2008) is that while some 82 per cent of examiners do either mention or allude to significance or contribution, a substantial proportion may never use the exact words 'original', 'significant' or 'contribution'. This begs the question, how are these terms being interpreted by examiners? Further, what is it that examiners are actually looking for? And if there is no mention, is there no perceived contribution?

In a more recent study some examiners during interview acknowledged that words such as 'original' can have a reasonably loose application. For example:

I think at times [this] is problematic because how much of an original contribution do you need to make? Some examiners take a view that it could be trivially new, if you like, because you're simply doing something in a different context, so there's a trivial novelty to it. ${ }^{2}$

One examiner from this study pointed out that it would be difficult to deny originality if the thesis focussed on 'a local topic that hadn't been done before'. Yet another was satisfied with 'just really simply something that I have never seen before'.

Others are less forgiving in their interpretation of original, significant and contribution. For example: 
By the time I get to a PhD I am expecting to see evidence that original research has been conducted and that that research and the way it is presented is at a level that is suitable for, and would be potentially publishable, in a quality peer reviewed journal in the field.

And:

I think maybe I am a bit old fashioned, but I do think it ought to be a contribution to knowledge. I think you really want to be able to see what this person has added, either by looking at material in a fresh way, applying theory in an interesting way, coming up with a methodology or a theory, recovering material that's been lost: there should be some genuinely original material to it.

In relation to theoretical contribution, if a candidate is not applying or coming up with their own theory from the research, examiners may interpret contribution as the candidate making the effort to position themselves theoretically and enter a debate. In other words, having something to say about theory if not necessarily developing or testing out a new theory. In a study that examined examiners' reference to candidate contributions to theory (Holbrook et al. 2014), it was found that mention of candidates successfully developing theory rarely occurred in examiner reports, suggesting that for most candidates this was not an expectation of the doctorate.

In creative fields, when examiners refer to originality and the contribution made in a doctoral thesis ${ }^{3}$, they communicate this variously using terms such as: 'original'; 'significant'; 'original contribution'; 'highly original’; 'original topic'; 'original perspective’; 'original scholarly work'; 'original and relevant'; 'original contribution to knowledge'; 'convincingly original'; 'significant and original contribution'; 'significant to [a field]'; 'substantial contribution to knowledge'; 'certainly contributing new knowledge'; 'new and potentially significant'; 'important contribution to theory'; 'theoretical contribution'; 'novel'; or 'unique'. Further comments that clearly indicate a perceived level of such a contribution include: 'valuable and publishable'; 'impactful within a field'; 'of publishable standard'; or 'worthy of publication'. There are also comments that refer to the opposite, such as 'not original', 'not yet making a contribution' and 'not publishable'. This variety of terminology and phrasing points not only to a spectrum of emphasis for examiners, but also to a phenomenon of composite qualities where it stands to reason that examiners will judge the work in context; hence the conceptualisation of contribution reflects an evaluative framework that is supple and dynamic.

Without reference to any of the above terms (i.e. in reports on creative work where there is no specific mention of significance, contribution, originality, newness or novelty), examiners in creative fields refer to key aspects of the work as being: 'clever'; 'compelling'; 'remarkable'; 'exciting'; 'interesting'; 'intriguing'; 'exemplary'; 'effective'; 'courageous'; 'venturesome'; 'brilliant'; 'illuminating'; 'staggering'; and 'beautifully situated'. These are descriptions that are perhaps inspired by the very inclusion of a creative project, because in non-research contexts such works can elicit similar emotional proclamations. All of these expressions may be interpreted to hint at a contribution aligned with quality, but quality in another form, not least the aesthetic of the work in whole or part (e.g. the lyricism of a poem, the language of a novel, the plotting of a screenplay). Intriguingly these types of expressions are not confined to 
creative fields. It has been found that doctoral examiners also use such expressions to refer to theses they judge as outstanding and especially coherent (see Mullins and Kiley 2002).

\section{How might supervisors help to facilitate contribution?}

If doctoral examiners are also supervisors, then from the section above we can assume that these supervisors need to know what a contribution is - original, substantial or otherwise - and as outlined, have a language with which to describe this. But how, if at all, does this transpose into their supervisory practices? Do they hinge their pedagogy on the concept of contribution, or do they trust that it will organically emerge as a matter of course? Are the expectations of contribution made explicit with candidates, or is it an implicit expectation that only comes into play explicitly shortly before submission?

Acknowledging Kroll's idea that examiners become important mentors to candidates through the feedback they provide, which then goes on to influence the discipline through the future work of the graduate (2013), the lead author of this article reports that while facilitating a contribution to knowledge has always underpinned his supervisory practice, it is only in more recent times that it has taken on a more explicit role. For example, and in alignment with the findings reported in the section above, it is through examining a large number of creative writing $\mathrm{PhDs}$ over the past five years that a much clearer understanding about what a contribution looks like has emerged. Not only this, what has also emerged is a stronger expectation for the candidate to clearly articulate where the contribution is located (e.g. theme, plot, action) and importantly - how it has been arrived at. In short, valuing contribution as the central quality of a PhD has led to higher expectations of articulating the methodological design of or approach to the project.

It is worth pointing out here, anecdotally, that a common reaction to the idea of contribution in creative writing goes something like this: 'It has to be new because nobody else has done it. It is a new story; it is fiction; it cannot not be new.' While this is not an untrue statement, it does not really answer the question of what a contribution is. Every $\mathrm{PhD}$ is new because it has not been done before. The key, of course, is contextualising to what the work is contributing. An original screenplay might contribute to the world in and of itself by the fact that it has never been written before, but to contribute to knowledge there has to be an awareness of the knowledge that already exists, and how the screenplay thus makes a contribution to that domain of knowledge. Just as a contribution to knowledge is different from a contribution to the world, new knowledge is markedly different from mere knowledge.

Similarly, just because a creative work is used to contribute to knowledge, it does not mean that the creative work 'is' a contribution, ipso facto. As can be seen from Wellington below, while in some disciplines 'presenting research in a novel way' might constitute a contribution, in creative practice disciplines this is surely a given. Practice is used as the mode of research; therefore, the resulting research will be presented in a non-traditional format. For this discipline, the creative writing artefact is an outcome of research (a research output) that 'does' research - performative, embodied (see, for example, Berkeley et al. 2016, Haseman 2006, Leavy 2013) - and so the important 
question becomes: in what specific ways does the creative work contribute to knowledge?

To assist creative writing PhD supervisors in the facilitation of contribution, we can turn to Wellington's seven categories of contribution (Wellington 2013: 1496-97) and consider how they might be applied to the type of work produced in the discipline. While this annotated list is clearly not exhaustive, it is intended to offer suggestions about the nature of contribution that not only ensure one is made, but that also highlight the importance of methodologically designing one and offering a clear articulation of it in the exegesis/dissertation/critical component.

Against each of Wellington's proposed contribution types below, then, we provide suggestions for what this could look like in the creative writing $\mathrm{PhD}$. We pay specific attention to the $\mathrm{PhD}$ as a unified thesis (argument) that contains critical and creative components: the $\mathrm{PhD}$ as one project guided by one research question or proposition, not two (or more) works researched and written independently. In this way, contribution becomes a synthesised effort expressed through a combination of creative and critical artefacts.

\section{Building new knowledge}

While this might seem fairly obvious, what new knowledge is actually needed for the discipline? What knowledge does not exist and what would be the use of having this knowledge? Ideas include:

- Original insights into an area of writing craft, for the benefit of other practitioners (and scholars).

- Analysis of the work/practice of an individual or group of practitioners, with a view to developing knowledge about a particular type of practice.

- Identifying and situating emerging genres or forms of creative writing that are not yet theorised.

\section{Using original processes or approaches}

This could be about applying an already known type of practice to a new form, genre or scenario, or finding a new way to practice based on a particular theory, idea or context. The key question to ask here would be, why is this original approach needed? Ideas include:

- Could screenwriting practices be adapted to the writing of poetry, for a specific effect?

- How might digital tools be used to compose a novel?

- What might a queered short story writing practice look like? 


\section{Creating new syntheses}

Not dissimilar to the former idea, this type of contribution would purposely draw together extant ideas and/or practices with a view to generating new ideas and/or practices. Again, why is this synthesis needed? What would individuals or groups benefit from this? Ideas include:

- Discerning patterns of practice by curating a history of the genre or form, with a view to creating a new or enhanced understanding.

- Creating practice-based tools from amalgamating previous techniques and processes, perhaps resulting in a new methodology for practice.

- Offering a theoretically nuanced/different version of existing knowledge, probably centred around practice, with a view to arguing for new action to take place based on this contribution.

\section{Exploring new implications, for either practitioners, policy makers, or theory and theorists}

In a way, this type of contribution underscores most, if not all, creative writing projects. The idea of 'implications' is well suited to the idea of practice, in the sense that understandings are not just theoretical, but are also applicable to a writing-based scenario or context. The notion of what implications creative writing has for theory is particularly interesting and, we would argue, less explored than for practitioners and/or industry. Ideas here include:

- Responding creatively to fundamental developments in arts-based policy, with a view to testing out how one is influenced by the other.

- Assessing what happens when new methods, such as those developed by industry, are used in a particular practice and/or context.

- Determining how particular writers respond to aspects such as digital advances and market demands, and what this can tell us about the future of that practice.

\section{Revisiting a current issue or debate}

This would assume that there is a clear need to revisit the issue or debate, perhaps because it has been neglected or perhaps because something happening 'now' requires action. Maybe other research has tried to tackle the issue or debate, but the findings are not satisfactory - especially for practitioners. Ideas include:

- Generating alternative ways to assess and respond to industry dictates, perhaps because a particular industry (such as prose fiction or film) has caused a sense of unease with practitioners.

- Theorising and designing creative approaches to social issues, with a view to generating wider participation (e.g. non-academics) so that the issue can be better tackled. 
- How might creative writing be a useful mode through which to interrogate this issue and debate; who would the end users of this research be; and what would the creative approach seek to achieve?

\section{Replicating or reproducing earlier work [differently]}

Common in the sciences, engineering and business, where products and systems need to be better and more efficient, what would be the advantage of going back to an earlier creative writing work, and how would it be done? What factors or variables would be different this time, and what would they be looking to achieve? Both the premise and system for enquiry would be important here. Ideas include:

- Adapting a creative work in a new context or via a new form, underpinned by a particular desire, need or practice-based context.

- Offering a creative exploration of an already known study, person or phenomenon, in order to contribute to this known work differently, for a specific purpose and/or end users.

- Does the inclusion of different tools or approaches, not available at the original time, change the findings in any way?

\section{Presenting research in a novel way}

As discussed above, this is a given for creative writing research - though the word 'novel' needs interrogation. Is, for example, a collection of short stories in and of itself and original approach to a topic, or do the short stories themselves need to be original - in style, form, voice, etc.? How would a research screenplay look/be different from an industry screenplay, and is there novelty in that? Ideas include:

- Using creating writing to offer counter representations to those presented in non-creative outlets and discourse.

- Developing a braided, multimodal or fictocritical work that combines theory, practice and reflection, thus presenting the thesis as one document that has its own internal voice and logic.

- How might creative writing be used to disseminate the results of a very scientific or statistical study or set of findings, and what would this contribute to the study or its findings?

\section{Conclusion}

We framed this article by asking 'what, where and how' is a contribution to knowledge in creative writing, with the aim of addressing current issues for the discipline and beginning to propose solutions and practices to resolve them. As we have explored, while the notion of contribution is central to the creative writing $\mathrm{PhD}$, it can take many forms, can be found in many places, and is arrived at in a multitude of ways. The only constant is that there are persistent differences in how contribution is perceived, 
approached and articulated - and as noted, by examiners as well as candidates and supervisors.

For Wellington, 'If the student and the supervisors have done their jobs together, that originality should be there anyway, it should emerge from the study. It needn't be about a substantive issue, it may be about methodology, or often both' (Wellington 2013: 1500). While this is all good and well in theory, why in practice is it complicated, contested and in some cases, ignored? If 'the doctoral examination can be viewed as a socially constructed encounter rather than a fully objective and impartial process' (Park 2005, cited by Wellington 2013: 1497), then how does this play out in creative writing? Wellington (2013) also sees the concept of doctorateness as a socially constructed concept subject to interpretations, but how does this play out in connection with contribution and setting the bar on standards? While disciplines might have specific understandings and examples of contribution, is the very notion of contribution original, significant or otherwise - contestable?

We might argue that in creative fields that are relatively new to the academy, whose candidates, supervisors and examiners often come from backgrounds that do not usually privilege academic research, there is still some way to go regarding standard understandings of what a contribution to knowledge looks like. As the section on examiners' discussions of contribution alluded to, perhaps the criteria being used to assess work either rubs up with that of the field itself (i.e. the creative writing industry), or else is altogether ignored in favour of what is known or felt about what makes a 'good' creative work. There is a clear sense of subjectivity underlying many examiners' comments about doctoral work in creative writing, which while cannot be avoided altogether, should be questioned and grappled with deeply if the discipline is to further move forward in the direction of quality research outcomes.

In this regard, we end by posing questions and propositions, which we might call the dimensions of contribution, to prompt serious consideration from supervisors and candidates about what is being contributed, where it can be found, and how it has been arrived at. The purpose here is not just to generate a strong awareness of the need for contribution, but moreover to provide a set of doctoral standards in the hope that creative writing can take a leap to the next level of research excellence and quality, including how contribution can be articulated clearly and successfully.

- Are examiners assessing effort over contribution? The candidate has done a lot of work, therefore award the PhD.

- What do examiners accept as doctoral work, and is this good enough? When is a creative writing artefact a doctoral creative writing artefact?

- Is assessment of the $\mathrm{PhD}$ holistic, or are examiners commenting on the creative and critical works separately? The combination of parts - the thesis as a whole - is what should be examined.

- What is the doctoral task of the creative writing PhD? Thinking and doing must be transformative, and assessed as such. Where is this evidenced across the thesis? 
- Is the creative work in a PhD exactly how it would have been written outside of a $\mathrm{PhD}$ ? Has the practice itself moved on, or only the understanding of how one practices?

\section{Endnotes}

1. Linda Candy (2006) would call this practice-based research. Candy does make some valuable distinctions between practice-based and practice-led research, but for our purposes here she does not fully interrogate what a contribution to knowledge looks like in the creative artefact: she emphasises that in practice-based research, the contribution is (mainly) made evident in the exegesis/dissertation.

2. The study referred to here is Holbrook et al.'s 'A cross national study of the relative impact of an oral component on PhD examination quality, language and practice' (2011-13). The study included 80 interviews with experienced examiners in England, Australia and New Zealand, and the collection and analysis of examiner reports (see Lovat et al. 2015). To satisfy HREC protocols, the reports and interviews were not matched. During interviews examiners were directly asked to comment on the qualities of doctoral work and less than half referred to originality, contribution or significance directly.

3. The sub-set of data referred to here was gathered during three projects (ARC DP034362; ARC DP0880092; ARC DP110103007) focusing on doctoral examination, and all included the collection of examiner reports. In each study report text was collected and core coded in exactly the same way to support direct comparison. The creative areas included music and drama, visual arts and creative writing. Each report was coded at a priori core categories including two categories used for fine grained analysis in this paper: 'significance and contribution' and 'summative comment'. Reports were, on average, 2.5 pages in length.

\section{Works cited}

Australian Qualifications Framework 2013, at https: //www.aqf.edu.au/sites/aqf/files/aqf-2nd-editionjanuary-2013.pdf (accessed 28 July 2017)

Arnold, Josie 2005 'The $\mathrm{PhD}$ in writing accompanied by an exegesis' Journal of University Teaching and Learning Practice 2 (1), 37-50, at http: //ro.uow.edu.au/jutlp/vol2/iss1/5 (accessed 25 February 2017)

Baker, Sue 2014 'Collegial conversations: the role of writing in creative arts doctoral education' i: Louise Ravelli, Brian Paltridge and Sue Starfield (eds) Doctoral writing in the creative and performing arts Faringdon: Libri, 33-50

Batty, Craig and Susan Kerrigan 2017 'Introduction’ in Craig Batty and Susan Kerrigan (eds) Screen production research: creative practice as a mode of enquiry Basingstoke, Palgrave Macmillan (forthcoming)

Berbary, Lisbeth A 2011 'Poststructural "writerly" representation: screenplay as creative analytic practice’ Qualitative Inquiry 17 (2), 186-96

Berkeley, Leo, Martin Wood and Smiljana Glisovic 2016 'Creative destruction: screen production research, theory and affect' Journal of Writing in Creative Practice 9 (1-2), 7-31

Candy, Linda 2006 Practice based research: a guide Creativity \& Cognition Studios, Sydney: U of Technology, at https: //www.mangold-international.com/_Resources/Persistent/ 764d26fd86a709d05e8d0a0d2695bd65fd85de4f/Practice_Based_Research_A_Guide.pdf (accessed 7 July 2017)

Clarke, Gillian and Ingrid Lunt 2014 'The concept of "originality" in the PhD: how is it interpreted by examiners?' Assessment \& evaluation in higher education 39 (7), 803-20 
Dally, Kerry, Allyson Holbrook, Anne P Graham and Miranda Lawry 2004 'The processes and parameters of fine art PhD examination’ International Journal of Educational Research 41(2), 136-62

Forbes, Anne-Marie 2014 'Doctoral research through music performance: the role of the exegesis' in Louise Ravelli, Brian Paltridge and Sue Starfield (eds) Doctoral writing in the creative and performing arts Faringdon: Libri, 263-79

Gibson, Ross 2017 'Foreword: cognitive two-steps’ in Craig Batty and Susan Kerrigan (eds) Screen production research: creative practice as a mode of enquiry Basingstoke, Palgrave Macmillan (forthcoming)

Hamilton, Jillian and Sue Carson 2013 Effective supervision of creative practice higher research degrees: literature review Brisbane, Australia: Queensland U of Technology, at http://supervisioncreativeartsphd.net/wp-content/uploads/2014/01/Supervision_Creative-arts_LitReview.pdf (accessed 12 March 2017)

Hamilton, Jillian 2014 'The voices of the exegesis: composing the speech genres of the practitionerresearcher into a connective thesis' in Louise Ravelli, Brian Paltridge and Sue Starfield (eds) Doctoral writing in the creative and performing arts Faringdon: Libri, 369-88

Haseman, Brad 2006 ‘A manifesto for performative research’ Media International Australia, Incorporating Culture \& Policy 118, 98-106

Holbrook, Allyson, Sid Bourke, Terence Lovat, Margaret Kiley, Brian Paltridge and Sue Starfield 2011-13 'A cross national study of the relative impact of an oral component on PhD examination quality, language and practice’, ARC DP110103007

Holbrook, Allyson, Sid Bourke, Hedy Fairbairn and Terence Lovat 2014 'The focus and substance of formative comment provided by PhD examiners’ Studies in Higher Education 39 (6), 983-1000

Hope, Sophie 2016 'Bursting paradigms: a colour wheel of practice-research’ Cultural Trends 25 (2), 74-86

Krauth, Nigel 2011 'The evolution of the exegesis: the radical trajectory of the creative writing doctorate in Australia' TEXT: Journal of Writing and Writing Courses 15 (1), at http: //www.textjournal.com.au/april11/krauth.htm (accessed 15 July 2016)

Kroll, Jeri 2013 'Creative synergies: exploring the process of supervising and examining the creative writing doctoral thesis’ TEXT: Journal of Writing and Writing Courses Special Issue 22, 1-17, at http://www.textjournal.com.au/speciss/issue22/content.htm (accessed 21 May 2015)

Leavy, Patricia 2013 Fiction as research practice: short stories, novellas, and novels New York: Routledge

Lovat, Terence, Allyson Holbrook, Sid Bourke, Hedy Fairbairn, Margaret Kiley, Brian Paltridge and Sue Starfield 2015 'Examining doctoral examination and the question of the viva' Higher Education Review 47 (3), 5-23

Lovat, Terence, Allyson Holbrook and Sid Bourke 2008 'Ways of knowing in doctoral examination: how well is the doctoral regime?’ Educational Research Review 3 (1), 66-76

Mullins, Gerry and Margaret Kiley 2002 'It’s a PhD, not a Nobel Prize': how experienced examiners assess research theses’ Studies in Higher Education 27 (4), 369-86

Parry, Sharon 2007 Disciplines and doctorates: higher education dynamics vol 16 Dordrecht: Springer

Phillips, Maggie, Cheryl Stock and Kim Vincs 2008 Dancing between diversity and consistency: refining assessment in postgraduate degrees in dance Canberra, Australia: Australian Learning and Teaching Council, at http://www.dancingbetweendiversity.com (accessed 16 September 2017)

Sempert, Mattie, Louise Sawtell, Peta Murray, Sophie Langley and Craig Batty 2017

'Methodologically speaking: innovative approaches to knowledge and text in creative writing research' New Writing: The International Journal for the Practice and theory of Creative Writing 14 (2), 205-22

Watkins, Ross and Nigel Krauth 2016 'Radicalising the scholarly paper: new forms for the traditional journal article’ TEXT: Journal of Writing and Writing Courses 20 (1), at: http://www.textjournal.com.au/april16/watkins\&krauth.htm (accessed 15 July 2016) 
Webb, Jen, Donna Lee Brien and Sandra Burr 2013 Examination of doctoral degrees in creative arts: process, practice and standards Canberra, Australia: Office of Learning and Teaching, at http://www.olt.gov.au/project-examination-doctoral-degrees-creative-arts-process-practice-andstandards-2010 (accessed 16 September 2017)

Wellington, Jerry 2013 'Searching for “doctorateness”' Studies in Higher Education 38 (10), 14901503

Wilson, Jenny 2014 'Artist-academic as doctoral student: navigating different expectations, frameworks and identities’ in Louise Ravelli, Brian Paltridge and Sue Starfield (eds) Doctoral writing in the creative and performing arts Faringdon: Libri, 199-218 